\title{
Por um Ateísmo Tranquilo: O Racionalismo de François Châtelet no Périclès et Verdi de Gilles Deleuze
}

[For a Quiet Atheism: François Châtelet's Rationalism in Périclès et Verdi by Gilles Deleuze]

\section{Marcelo de Sant'Anna Alves Primo®}

Resumo: Em 1988, Gilles Deleuze dedica Periclès et Verdi, ao amigo François Châtelet. Quando fora chamado pelo Collége International de Philosophie para participar das últimas mesas redondas dedicadas à morte do amigo, Deleuze vê na recusa de deus e de toda transcendência châteletianas uma serenidade ateia depois de Nietzsche. À época de seus estudos de Filosofia na Sorbonne, Châtelet pela primeira vez entra em contato com Deleuze, e a partir daí constituir-se-á a sua projeção como filósofo da história e como filósofo político. Nesse sentido, eis o seu interesse pela filosofia de Châtelet: gradativamente refaz a trajetória filosófica do amigo e, ao mesmo tempo, conjura a sua morte e homenageia-o postumamente através da ressonância do pensamento de Châtelet em sua própria filosofia.

Palavras-chave: Chatêlet; Deleuze; filosofia; ateísmo.

Abstract: In 1988, Gilles Deleuze dedicates Periclès et Verdi to his friend François Châtelet. When Deleuze had been summoned by the Philosophie Collective International to attend the last roundtables devoted to his friend's death, he saw in the refusal of god and all Chateletian transcendence an atheistic serenity after Nietzsche. At the time of his studies of philosophy at the Sorbonne, Châtelet first comes into contact with Deleuze, and from there his projection will be constituted as a philosopher of history and as a political philosopher. In this sense, here is his interest in Châtelet's philosophy: it gradually retraces his friend's philosophical trajectory and at the same time conjures his death and posthumously honors him through the resonance of Châtelet's thought in his own philosophy.

Keywords: Chatêlet; Deleuze; philosophy; atheism.

\footnotetext{
${ }^{*}$ Professor Titular do Colégio de Aplicação da Universidade Federal de Sergipe (UFS) e do PPGFIL-UFS. E-mail: marceloprimo_sp@hotmail.com. ORCID: https://orcid.org/0000-0002-7406-5371.
} 
"O ateísmo não é um drama, ele é a serenidade do filósofo e a conquista da filosofia."

Gilles Deleuze, O que é a filosofia?

\section{1- Introdução}

Pode causar estranhamento aos mais íntimos do pensamento de Deleuze que este, já tendo escrito na década de oitenta do século passado os dois monumentais volumes de Capitalismo e Esquizofrenia juntamente com Guattari, em 1988 dedicasse um trabalho ao racionalista François Châtelet. Quando fora chamado pelo Collège International de Philosophie para participar das últimas mesas redondas dedicadas à morte do amigo e filósofo da história, Deleuze vê na recusa de Deus e de toda transcendência châteletianas uma serenidade ateia depois de Nietzsche. À época de seus estudos de Filosofia na Sorbonne, Châtelet pela primeira vez entra em contato com Deleuze, e a partir daí constituir-se-á a sua projeção como filósofo da história e como filósofo político. No pósmaio de 1968, ele começa a tra- balhar com Foucault e Deleuze na instauração do departamento de Filosofia da Universidade de Vincennes (Paris VIII), conduzindo-o durante uma década. Em 1983 colaborará com a criação do Collège International de Philosophie e morre em 1985. Nesse sentido, se Deleuze "nunca parou de comentar outros autores e, ao fazêlo, sempre afirmou um pensamento próprio e original" (ZOURABICHVILI, 2016, p. 35), isso bastaria para explicar o seu interesse pela filosofia de Châtelet, pois gradativamente refaz a trajetória filosófica tanto dos amigos como dos intercessores, ao mesmo tempo conjurando a sua morte e homenageando-o postumamente através da ressonância do pensamento de Châtelet em sua própria filosofia.1

\footnotetext{
${ }^{1}$ Segundo Luiz B.L. Orlandi, "No caso deste pequeno livro, essa atração por linhas virtuais traduz-se como concentrada atenção a certos singularizadores nocionais. Graças a estes, descortina-se uma breve tessitura de conceitos, esse lugar de intersecção (mas não de fusão) das duas vertentes: a obra de Châtelet e a de Deleuze. Então, é como se tivéssemos neste livro o esboço conceitual de uma virtualidade comum a esses dois pensadores contemporâneos. É essa comum virtualidade (mas estendendo-se esse comum como transmutividade, como complexa diferenciação) que cada uma dessas obras vai erigindo enquanto tração distintamente sua própria maneira de pensar, seu modo singular de revirar-se nela. Sendo assim, caberia lembrar alguns poucos conceitos que, variando em cada um desses modos de pensar, tornam possível pelo menos entrever seu plano de coexistência" (p. 1).
} 
2 - O Racionalismo de François Châtelet segundo Deleuze

Logo de início, Deleuze levanta a seguinte questão: "François Châtelet sempre se definiu como racionalista, mas qual racionalismo?" (1988, p. 7, tradução e grifo nosso)2, Referindo-se sempre aos clássicos da Filosofia, define-se, antes de qualquer coisa, como um aristotélico, mas distinto de um tomista devido, sem margem de dúvida, à "maneira de recusar Deus e toda transcendência. Todas as transcendências, todas as crenças em um outro mundo ele chama de 'pretensões'” (Id. Ibid.). Por meio desse repúdio às transcendências em seu caráter singular e plural, jamais houve nesse sentido uma filosofia tão tranquilamente ateia, à exceção de Nietzsche. Deleuze aqui refina a sua definição do que seja um ateísmo tranquilo, como uma "filosofia que Deus não é um problema, a inexistência ou mesmo a morte de Deus não são problemas mas, ao contrário, condições que é preciso considerar como adquiridas para fazer surgir os verdadeiros problemas: não há outra modéstia. Jamais filosofia alguma se instalou tão firmemente em um puro campo de imanência" (Id. Ibid.). Nesse sentido, se o filósofo é aquele que descreve e pensa as mutações do pensar, colocando a filosofia a serviço da imanência, optando por uma geologia em vez de uma genealogia e vendo que o verdadeiro problema "de modo algum é da ordem de crer ou não crer em Deus" (ZOURABICHVILI, 2016, p. 95), então essa tendência filosófica instalada nesse plano puro da imanência é uma escolha política, fazendo vir à tona os verdadeiros problemas à medida que libera gritos, dores e vozes sufocadas, uma vez que almeja escapar à disseminação do intolerável. O combate no campo da imanência é a antítese do jogo conformista propiciado pelas máquinas produtoras de universais, subjugando os outros "ao domínio de estratégias ou focos transcendentes, sejam estes a Razão, a racionalidade de presidentes da república, líderes de grupelhos, interesses poderosos ou deuses quaisquer" (ORLANDI, p. 2).

Segundo Deleuze, o campo de imanência é constituído por uma relação "Potência-Ato", sendo que essas duas noções só existem em correlação, como que siamesas. É por aí que "Châtelet é aristotélico, pois ele experimenta uma espécie de fascínio pela potência: o homem é potência, o homem é matéria" (1988, p. 8). Contudo,

\footnotetext{
${ }^{2}$ Todas as traduções das passagens do texto de Deleuze são de minha autoria.
} 
Deleuze cita uma passagem do livro Chronique des idées perdues do amigo, quando indica que o seu principal interesse é a potência ou o que faz o poder ser poder, que causa prazer em ser exercida na medida do possível, intentando compreender e descobrir os mecanismos de captação de potência. Segundo Châtelet, só assim é possível ter gosto por ela, manter ela viva dentro de si e despertá-la ao seu redor, definindo-a como liberdade (Id. Ibid., p. 9). Deleuze indaga duplamente: como passar da potência ao ato e qual é o ato dessa potência? Ele afirma que o ato é a razão, mas esta em um sentido bem peculiar, pois

a razão não é uma faculdade, mas um processo e consiste precisamente em atualizar uma potência ou formar uma matéria. Há um pluralismo da razão, porque não temos motivo algum para pensar nem a matéria nem o ato como únicos (1988, p. 9).

A essa altura, como pode ser traduzido aqui o aristotelismo de Châtelet? Significa a instauração de relações humanas em uma multiplicidade qualquer independente de sua envergadura, limpando o caminho para devires de- mocráticos e combatendo com o intuito de contornar demolições sempre ameaçadoras aos indivíduos e às coletividades. Havendo a exigência de o combate ser acurado com o seu próprio estilo, ele não pode sucumbir a apelos "a uma 'cidade ideal' ou a um 'Estado universal de direito'. Com efeito, esse combate privilegia a 'singularidade' que não é precisamente o individual, mas o caso, o acontecimento, uma configuração de 'acontecimentos', um 'devir ativo', uma 'decisão'”' (ORLANDI, p. 2). Assim, Deleuze afirma que o próprio ato, sendo relação, é sempre político e a razão, por sua vez, sendo processo, é política (op. cit., p. 9), não havendo psicologia, mas uma "política do eu", não havendo metafísica, mas uma "política do ser", não havendo ciência, mas uma "política da matéria", já que o homem "é responsável pela própria matéria" (Id. Ibid., p. 10). O autor cita o exemplo da faixa musical. Esta, sendo uma matéria sonora, é um processo de racionalização que consiste em instaurar relações humanas nessa matéria, de tal maneira que ela atualize a sua potência e torne-se ela mesma humana que, na verdade, seria o exemplo preciso para mostrar através dos órgãos dos sentidos a imanência entre o homem e a natureza, pois a orelha torna-se orelha humana 
quando o objeto sonoro torna-se musical. Deleuze aqui aponta para o todo bastante diverso dos processos de racionalização que constituem o devir ou a atividade humana, a Práxis ou as práxis, pois "não sabemos se existe a esse respeito uma unidade humana, do ponto de vista histórico ou do ponto de vista genérico" (Id. Ibid.).

\section{3 - As Definições de Potência e Ato}

Caso existisse uma matéria especificamente humana, uma potência pura distinta do ato capaz de atrair o fascínio dos homens, ela não seria liberdade neles sem mostrar-se antes como o seu contrário, ou "captação" nos termos de Châtelet, isto é, seria um ato obtuso da potência, oposto ao ato capaz de realizá-la (DELEUZE, 1988 , p. 11). Seria um reverso, uma privação ou uma alienação da razão, como se aí existisse uma relação não-humana, mas interior ou imanente à própria relação humana, tornando a liberdade uma capacidade para o homem vencer o homem ou de ser vencido. Aqui, a potência é o pathos, ou seja, a passividade, mas esta sendo, antes de qualquer coisa, a potência de receber os golpes e de desferilos, como uma estranha resistência. Deleuze afirma que é possí- vel fazer uma história dos sistemas de dominação na qual sempre se exerce a atividade dos mestres, "mas esta não seria nada sem o apetite dos que, em nome dos golpes que recebem, aspiram a dálos" (Id. Ibid.). Nesse sentido, exercido ou suportado, o poder é tanto uma atividade existencial social humana como é, concomitantemente, a passividade de sua existência natural. Dessa simultaneidade da potência e seu reverso, Châtelet extrai exemplos como o da união entre a terra e a guerra sob a pena de Claude Simon e o marxismo que jamais cindiu a existência ativa do homem histórico da existência passiva de um ser natural que é o seu duplo. Recorrendo a uma citação do livro de Châtelet Questions, Objections, Deleuze indica que a razão e o seu oposto (a irracionalidade) é um tema filosófico sempre recorrente, que pretende uma ciência crítica da passividade efetiva, solo da humanidade. O homem morre não pelo simples fato de ser mortal, mas porque não come o suficiente, porque é privado das necessidades mínimas e reduzido à animalidade. Nisso o materialismo histórico tem a sua parcela de contribuição, pois refresca a memória dos homens com esses fatos e estabelece os fundamentos do que seria o método de análise dos mecanismos que governam 
em uma determinada época o fato da passividade (Id. Ibid., p. 12.)

Deleuze entende que há valores inerentes ao pathos: 1) um desespero do mundo, que se apresenta recorrentemente em Châtelet com uma polidez exemplar. Sempre havendo entre os homens a demolição, seria melhor a destruição de si próprios sob condições agradáveis e até mesmo romanescas. E se a vida, certamente, é um processo de demolição, essa certeza "soa como uma constatação de imanência" (Id. Ibid., p. 13). Deleuze alude ao único romance escrito por Châtelet, Les annés de demolition, de inspiração em Fitzgerald, onde a elegância não é perdida de vista em um desastre, onde mesmo a tentação da morte se dá em um elemento sublime como a música. Faz-se necessário levar em conta o vetor de destruição que pode atravessar um indivíduo ou toda uma coletividade, Péricles ou Atenas. O primeiro livro de Châtelet, justamente intitulado Périclès, é a imagem plena do herói ou grande homem Péricles, "mesmo em sua 'passividade', mesmo através de sua falha, que será a falha da democracia, mesmo seguindo o inquietante vetor" (DELEUZE, 1988, p.13); 2) o segundo valor do pathos seria a polidez, grega, que já seria o esboço das relações humanas, "o início de um ato da razão"
(Id. Ibid.). As relações humanas têm o seu início em uma métrica, uma organização do espaço que é o sustentáculo da cidade, uma arte de estabelecer distâncias entre os homens que não são hierárquicas, porém, geométricas, distâncias que não estão nem muito perto nem muito longe, evitando dar ou receber golpes. Segundo Deleuze, a lição ensinada pelos gregos através desse encontro dos homens como um rito, um rituel d'immanence, foi não deixar os homens estagnarem-se em um centro fixo, "mas adquirir a capacidade de transportarem consigo mesmos um centro para organizar todos ou totalidades de relações simétricas e reversíveis efetuadas por homens livres" (1988, p. 14). Poder-se-ia ter em conta que isso não bastaria para vencer o desespero do mundo, já que há cada vez menos homens polidos, contudo, a polidez de Châtelet só seria uma espécie de disfarce para um terceiro valor do pathos: 3) uma bondade calorosa, não estando em consideração aqui o nome que convém, enquanto esta qualidade tenha profundamente pertencido à Châtelet, sendo mais do que um valor, sendo uma disposição do pensamento, um ato do pensamento que particularmente significa

não saber de antemão 
como alguém, eventualmente, achar-se-á capaz de instaurar nele e fora dele um processo de racionalização. Certamente há em todos os casos perdidos, o desespero. Mas se há uma chance de alguém que aí tenha necessidade, como procede para sair de suas demolições? Talvez todos nascemos sob um sol de demolição, mas não desperdiçaremos nenhuma chance. Não há Razão pura, ou racionalidade por excelência. Há processos de racionalização, heterogêneos, muito diferentes segundo os domínios, as épocas, os grupos e as pessoas (Id. Ibid., p.14-15).

Deleuze anuncia que a Razão não pode ficar aprisionada a um único modelo ou definição. O seu pluralismo se dá em processos diversos conforme os seus campos de atuação, tempos e lugares, indivíduos e grupos sociais. O processo de racionalização, enquanto razão imanente, inerente ao pathos, não pode enclausurar-se em uma fixidez que paralisa os atos do pensar. É caracterizado por sua provisoriedade em determinados momentos históricos e políticos, não podendo mais ser entendida como eterno.

\section{4 - O Pluralismo da Razão}

Em seus últimos livros, Michel Foucault conduzia esse pluralismo da razão para uma análise das relações humanas que engendraria o projeto de uma nova ética oriunda do que entendeu como "processos de subjetivação", mostrando as bifurcações e a historicidade quebrada de uma razão sempre em estado de alienação ou liberação nas relações do homem consigo mesmo. Nesse sentido, a Foucault foi necessária a ida aos gregos não para ver neles o milagre da razão - como defendia John Burnet no seu livro A Aurora da Filosofia Grega (chamado por Deleuze de "miserável milagre" ), mas somente para dar um diagnóstico do primeiro esboço de um processo de racionalização, seguido posteriormente por outros autores, sob diferentes condições e determinadas épocas e lugares. Mais do que isso, ele definiu a cidade grega por uma relação determinável como rivalidade dos homens livres ou cidadãos, na extensão de uma racionalização e de uma subjetivação, nas quais a um homem livre era impossível comandar outros homens livres, da mesma maneira como era capaz de comandar a si próprio. Este 
era o ato o ou processo particularmente grego, no qual não era possível empreender um ato fundador, mas um fato singular em uma cadeia rompida. Para Deleuze, é aqui que os pensamentos de Foucault e Châtelet se encontram, pois também para este último

a racionalização é também um processo histórico e político que conhece com Atenas a sua primeira ocorrência, mas também a sua falha e seu afastamento, Péricles, do qual afastar-se-ão outros acontecimentos tomados em outros processos. Atenas não foi o advento de uma razão eterna, mas o fato singular de uma racionalização provisória, especialmente brilhante (1988, p. 17).

Nesse sentido, sob a pena de Châtelet está denunciada a outrecuidance de uma razão universal, pois quando é reivindicado o direito a uma razão universal, incorre-se no erro da pretensão que é, na verdade, uma "impolidez metafísica" que consistindo em reconhecer "na razão uma faculdade humana e somente humana, uma faculdade dos fins do homem, sustentamoslhe uma transcendência ainda teológica" (DELEUZE, 1988, p. 17). Deleuze classifica o empirismo de Châtelet como racional e, ao mesmo tempo, seu racionalismo de empírico e pluralista (Id. Ibid., p. 18). O conceito chateletiano de empiria depende de dois princípios, a saber: 1) o abstrato nada explica, e sim ele que deve ser explicado e 2) o universal não existe, existindo somente o singular, a singularidade, sendo esta definida não como individualidade, mas "o caso, o acontecimento, o potencial, ou antes a repartição dos potenciais em uma matéria dada" (DELEUZE, 1988, p. 19). Fazer um mapa político de um indivíduo, de um grupo ou de uma sociedade é a mesma coisa, pois tratar-se-á de estender uma singularidade até avizinhar-se de uma outra, produzindo uma configuração de acontecimentos, tão rica e consistente quanto for possível. Para Deleuze, somos historiadores quando somente "sabemos retomar a operação que o próprio Péricles fez, esta conexão, esta conjunção de singularidades que permaneceriam latentes e isoladas sem uma política a qual se dá corretamente o nome de Péricles" (Id. Ibid.). Mesmo o indivíduo mais insignificante é um campo de singularidades que só obtém seu nome próprio das operações 
que ele empreende sobre si e na vizinhança para daí haurir uma configuração extensível. Deleuze relembra o que Châtelet diz de si mesmo, que teve uma educação pequeno-burguesa, foi influenciado por Hegel, vivendo um desses períodos históricos que deixam enferma qualquer alma um pouco sensível. Independentemente da matéria considerada, é o que chamar-se-á de a empiria ou história no presente, pois isso que é atualizar a potência ou tornar ativo. É na vida e seu prolongamento, como da razão e de seu processo, uma vitória sobre a morte, visto que não há outra imortalidade que a história no presente, sem outra vida a não ser aquela que conecta e faz convergir as vizinhanças, chamada por Châtelet de decisão: "Châtelet chamálo-á de 'decisão' e toda a sua filosofia é uma filosofia da decisão, da singularidade da decisão, em oposição aos universais de reflexão, de comunicação..." (Id. Ibid. p. 20-21). Estando ou não em Atenas, e se toda ação é "pericleana" e se o que se destaca dessa ação é uma decisão, Deleuze mostra que para Châtelet, o peso do empírico se impõe como multiplicidade, ou como todo plural, empírico e histórico. Contudo, histórico aqui ganha um contorno bem preciso, pois não é entendido como o trabalho do historiador, que para ser objetivo tem que se manter à distância e constituir um objeto que supostamente só é pertencente ao passado, mas no sentido de uma história do presente (Id. Ibid., p. 21). Assim, se o processo de racionalização se mostra como a atualização de uma potência, como o tornar ativo, como produção de relações humanas, como prolongamento de singularidades e como decisão, logo é fazer o movimento, pois "todo filósofo invocando o concreto sempre reivindicou 'fazer o movimento' antes de pensá-lo na abstração do universal" (DELEUZE, 1988, p. 21) $)^{3}$. O movimento é o próprio ato da potência, pois fazer o movimento é passar ao ato, instaurar a relação humana, e decidir não é querer fazer o movimento, mas fazê-lo. Deleuze concede que nem todo movimento é processo de racionalização, mas se Châtelet é aristotélico, é porque atribui à distinção entre movimento natural e movimento forçado um valor prático histórico notável: o mo-

\footnotetext{
${ }^{3}$ Para François Zourabichvili, esse seria o problema do hegelianismo apontado por Deleuze: "Eis por que o hegelianismo não é um erro, mas um fenômeno ao mesmo tempo pior e mais interessante: o desenvolvimento de uma ilusão necessária, transcendental. Era inevitável que Hegel viesse a atribuir ao negativo o papel de motor no pensamento, mas permanecendo no nível da representação. Sem dúvida, o negativo é a melhor maneira de representar o movimento; mas de representá-lo, justamente, e não fazê-lo" (2016, p. 86, grifo nosso).
} 
vimento forçado vem sempre do alto, de uma transcendência que lhe dá um fim, de uma mediação do pensamento abstrato que lhe impõe um curso, recompondo-o incessantemente com linhas retas antes mesmo de tê-lo empreendido, de uma razão supostamente universal; contrariamente, o movimento natural é composto de singularidades e só acumula vizinhanças, deslocando-se em um espaço que criou de acordo com os seus desvios ou suas inflexões, procedendo por conexões que jamais são preestabelecidas, indo do coletivo ao individual, do interior ao exterior, do voluntário ao involuntário e inversamente. Assim, citando Châtelet, Deleuze arremata:

Se a razão pode ser considerada como uma faculdade natural, é precisamente como processo, enquanto ela encontra a si mesma 'nos movimentos mais singulares, produzidos pelas trajetórias entrelaçadas' construindo um espaço volumoso que vem, avança, que se dobra sobre si, se dilui, explode, aniquila-se, implanta-se

$$
\text { (Id. Ibid., p. 23). }
$$

A naturalidade ou o movimento natural da faculdade da razão é algo processual, que se opõe diametralmente ao movimento forçado da transcendência. A Razão não segue um caminho préestabelecido. Movimenta-se naturalmente em diversas direções e adquire diversas formas, em um processo que fará com que ela encontre a si própria não por sua retidão, mas através de seus descaminhos ou desvios. ${ }^{4}$ Este movimento não vem dos céus, não é universal nem abstrato, mas imanente e plural.

\section{5 - Conclusão: O Ateísmo Tran- quilo como Rejeição das Abstra- ções Filosóficas}

Em seu livro Conversações, no capítulo "Rachar as coisas e rachar as palavras", que é uma entrevista a Robert Maggiori na edição do Libération de 2 e 3 de setembro de 1986, Deleuze fala sobre a amizade de longa data com Châtelet, este dizendo que eles eram do "mesmo time" e tinham os "mesmos inimigos". Eis a resposta:

\footnotetext{
${ }^{4}$ Em Foucault, Deleuze afirma algo que poderia ser aplicado à insuficiência de definir a Razão por sua eternidade e universalidade: "É evidente que toda forma é precária, pois depende das suas relações de forças e mutações" (2005, p. 139).
} 
- Penso que sim. Châtelet tinha um sentimento vivo disso tudo. Ser do mesmo time é também rir das mesmas coisas, ou então calar-se, não precisar 'explicar-se'. É tão agradável não ter que se explicar! Tínhamos também, possivelmente, uma concepção de filosofia. Não possuíamos o gosto pelas abstrações, o Uno, o Todo, a Razão, o Sujeito (1992, p. 108-109).

Se o ponto de partida de toda a reflexão sobre o pensamento de Châtelet foi a identificação com o "ateísmo tranquilo" de seu companheiro do Collège International de Philosophie e a constatação que não se trata mais de saber quem vai vencer o embate sobre a existência, a inexistência e a interferência dos deuses na terra, Deleuze caminha junto com Châtelet quando afirma em $O$ que é a filosofia? que o pensamento cristão não produz conceitos senão pelo seu ateísmo, pelo ateísmo mais recôndito do que em qualquer outra religião e para os filósofos "o ateísmo não é um problema, a morte de Deus menos ainda, os problemas só começam a seguir, quando se atingiu o ateísmo do conceito" (DELEUZE, 1992, p. 121). Sendo para Deleuze a imanência o baluarte de toda a filosofia, já que assume para si todos os percalços a serem enfrentados e suporta todas as condenações, perseguições e injúrias direcionadas a ela, é porque o problema da imanência está muito longe (se é que algum dia foi) de ser meramente abstrato e/ou teórico. E para os mais serenos e tranquilos, ainda é estranho que "tantos filósofos ainda assumam como trágica a morte de Deus. O ateísmo não é um drama, ele é a serenidade do filósofo e a conquista da filosofia" (Id. Ibid.) O processo de racionalização exige e implica em uma tranquilidade que permite ver que a imanência da razão está relacionada com a práxis intrínseca aos atos do pensamento. Esse movimento natural não está enredado nem comprometido com discussões abstratas se os deuses existem, inexistem ou se são providentes recompensando os bons e punindo os maus. Assim, o ateísmo tranquilo de Deleuze mostra que, diante desse dado, sempre viverá e sobreviverá o homem, conduzindose serenamente no mundo com o ateísmo que lhe é imanente e, em consequência, "pacificamente sem Deus” (CHABBERT, 2018, p. 50). 


\section{Referências}

CHABBERT, Marie. “On Becoming-Secular: Gilles Deleuze and the Death of God”, in: Working Papers in the Humanities. Cambridge: MHRA, 2018, vol. 13, p. 50-59.

DELEUZE, Gilles. Périclès et Verdi: la philosophie de François Châtelet. Paris: Les Éditions de Minuit, 1988. Conversações. Trad. de Peter Pál Pelbart. São Paulo: Ed. 34, 1992.

. O que é a filosofia? Trad. de Bento Prado Júnior e Alberto Alonso Muñoz. São Paulo: Ed. 34, 1992. . Foucault. Trad. de Cláudia Sant'Anna Martins. São Paulo: Brasiliense, 2005.

ORLANDI, Luiz Benedicto Lacerda. “Combater na imanência” , in: http://www.pucsp.br/nucleodesubjetividade/Textos/orlandi/combater_na_imanencia.pdfacessado em 28/02/2017.

ZOURABICHVILI, François. Deleuze: uma filosofia do acontecimento. Trad. de Luiz B. L. Orlandi. São Paulo: Ed. 34, 2016.

Recebido: 20/11/2019

Aprovado: 07/01/2020

Publicado: 26/01/2020 